\title{
Uneven Futures of Human Lifespans: Reckonings from Gompertz Mortality Rates, Climate Change, and Air Pollution
}

\author{
Caleb E. Finch ${ }^{a}$ Hiram Beltrán-Sánchez ${ }^{a}{ }^{a}$ Eileen M. Crimmins ${ }^{a}$ \\ a'Davis School of Gerontology and Dornsife College, University of Southern California, Los Angeles, Calif., and \\ ${ }^{b}$ Center for Demography of Health and Aging, University of Wisconsin-Madison, Madison, Wisc., USA
}

\begin{abstract}
Key Words
Lifespan · Gompertz model · Minimum mortality .

Infections · Global warming · Air pollution
\end{abstract}

\begin{abstract}
The past 200 years have enabled remarkable increases in human lifespans through improvements in the living environment that have nearly eliminated infections as a cause of death through improved hygiene, public health, medicine, and nutrition. We argue that the limit to lifespan may be approaching. Since 1997, no one has exceeded Jeanne Calment's record of 122.5 years, despite an exponential increase of centenarians. Moreover, the background mortality may be approaching a lower limit. We calculate from Gompertz coefficients that further increases in longevity to approach a life expectancy of 100 years in 21 st century cohorts would require $50 \%$ slower mortality rate accelerations, which would be a fundamental change in the rate of human aging. Looking into the 21 st century, we see further challenges to health and longevity from the continued burning of fossil fuels that contribute to air pollution as well as global warming. Besides increased heat waves to which elderly are vulnerable, global warming is anticipated to increase ozone levels and facilitate the spread of pathogens. We anticipate continuing socioeconomic disparities in life expectancy.

(c) 2013 S. Karger AG, Basel
\end{abstract}

(C) 2013 S. Karger AG, Basel

0304-324X/13/0602-0183\$38.00/0
Since 1800, survival to older ages has increased progressively, effectively doubling life expectancy (LE), whether measured at birth [1] or at later ages [2]. This essay considers demographic evidence that human longevity is approaching a maximum $\left(\mathrm{L}_{\max }\right)$ with current medicine, and addresses evidence from climate change that health across the lifespan could be challenged by environmental deterioration associated with global warming. As briefly noted in two 2010 reports on climate change from the US National Academies of Sciences (NAS) [3, 4], the elderly are among the disadvantaged populations with particular vulnerability.

We first considered the demographic history of mortality rates across the lifespan. Using Sweden as an example because of its unique national data since 1750, we showed that the J-shaped mortality rate profiles for cohorts have progressively dropped since 1800; the Swedish mortality profile is well matched by other industrializing countries $[5,6]$. Across all postnatal ages, LE has at least doubled in the last 150-200 years due to the progressively declining mortality from infections with improved sanitation, water supply, and nutrition in the 19 th century, followed by immunization and pasteurization in the early 20th century, and lastly by antibiotics after 1950 [5-7].

The J-shaped mortality curves of modern populations may be divided in 4 phases: the initially high mortality

\section{KARGER}

E-Mail karger@karger.com

www.karger.com/ger
Caleb E. Finch

Davis School of Gerontology and Dornsife College

University of Southern California

Los Angeles, CA 90089-0191 (USA)

E-Mail cefinch@usc.edu 
Fig. 1. Human mortality trends by age from the Human Mortality Data Base (HMDB). a Minimum mortality rates or lowest mortality rates in human populations for 5 countries at age 10-20 for historical cohorts from England-Wales, Sweden, Switzerland, and the USA show progressive decline with improving overall mortality as the Gompertz curves descend. The 'minimum mortality' phase may extend beyond age 30 . With the virtual elimination of mortality from infections in the latter years of the 20th century, the minimum mortality is approaching a limit of about 2 deaths per 10,000 per year. Redrawn from [8]. b, c Observed Gompertz parameters from cohorts born between 1800 and 1920 for Sweden, Norway, Denmark, France, Italy, Netherlands, Switzerland, and England and Wales: $\mathrm{m}(\mathrm{x})$ = intercept [exp]slope $(\mathrm{x})$, where age is $\mathrm{x}$, intercept is mortality rate at age 40 , and slope is calculated for ages 40-90. b Intercept (background mortality) at age 40 (ln scale). c Slopes; at far right, the calculated slopes which would be required for LE at birth of 100 years, assuming basal mortality at age 40 in the 2000 period. This calculation used the Gompertz survival equation [9] as for $\mathrm{L}_{\max }$ values cited in the text above.

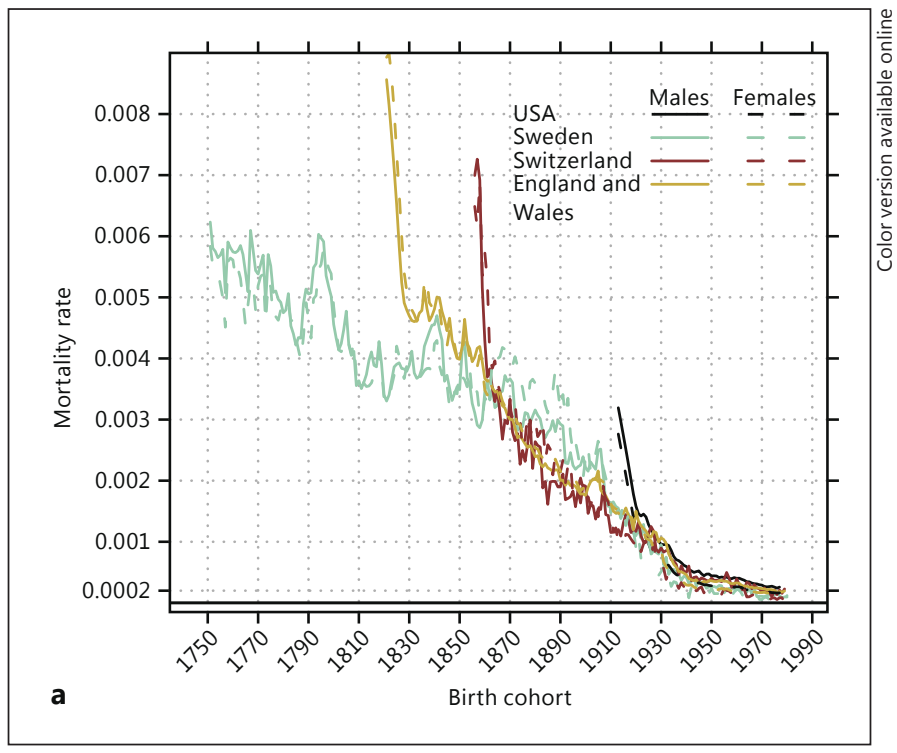

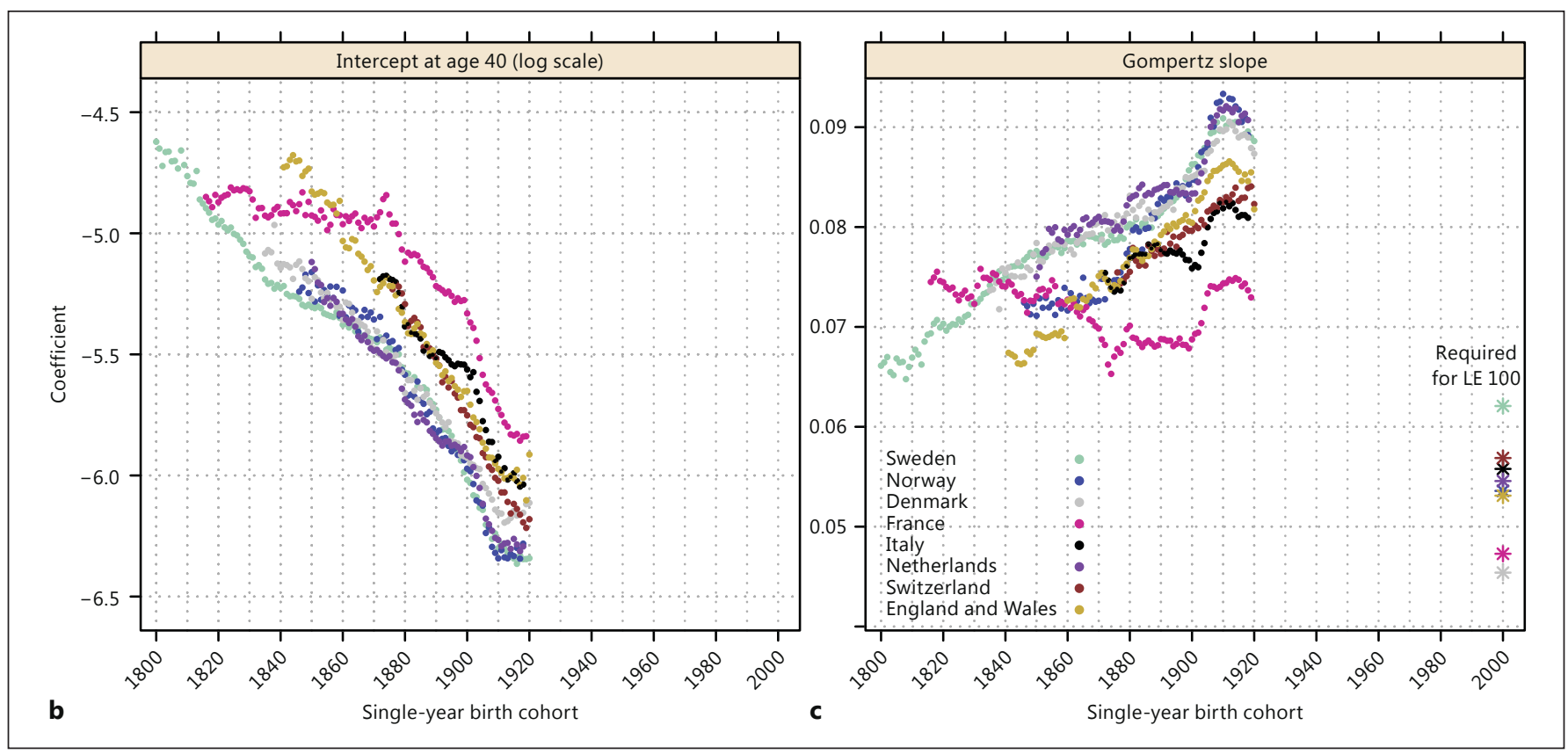

phase of infants and children declines with adolescence to a phase of lower background mortality that we describe as 'minimum mortality' after 10 year of age and lasting 10 or more years [8], which is followed by a third phase of accelerating mortality (Gompertz curve). For economically developed countries, mortality accelerations begin their exponential upsweep after 30-40 years of age, which is described by the Gompertz mortality model. A putative fourth phase of mortality plateau at advanced ages when mortality approaches or exceeds 0.5 /year is discussed below.
Currently the minimum mortality at $10-30$ years of age is approaching 2 deaths/year/10,000 [8, 9] (fig. 1a). There must be some lower limit to young adult mortality because of accidents, residual birth defects, and rare dominant heritable diseases. The approaching lower limit in mortality requires that further gains in the 21st century can only come from slowing or delaying mortality acceleration in midlife. Further analysis may identify the duration of minimum mortality, which also defines the onset of the Gompertz curve. Because of demographic variabil- 
ity, we use mortality rates at age 40 to approximate the foot of the Gompertz curve [9].

Using the Gompertz model for mortality rate accelerations after age 40 , the foot of the acceleration curve (Gompertz intercept) shows progressive decrease of the initial mortality rate since 1800 (fig. 1b). Reciprocally, the rate of mortality acceleration with age increased progressively as overall mortality dropped up to the cohort born in 1900 (fig. 1c). This relationship was first noted by Strehler and Mildvan [10] in 1960 for cross-sectional data, which we extended to cohorts [9].

Gender differences in minimum mortality are consistent with women having lower Gompertz curves than men at age 40 in the 19th and 20th centuries, represented in the lower values at age 40, the 'Gompertz intercept', calculated elsewhere [9]. Moreover, women born in the 20th century have shown slower mortality rate accelerations than men [9]. Both parameters contribute to their greater LE and the greater $\mathrm{L}_{\max }$ than males (discussed below).

At later ages, the mortality picture remains incomplete, despite major efforts on oldest-old demography. The 1998 analysis by Vaupel et al. [11] suggested that mortality rates decelerated towards a plateau after age 80 , with a possible decline in mortality rates after 100 (the fourth phase of the mortality trajectory above). While mortality rate plateaus at later ages are well documented for lab flies and worms [11], they have not been shown for lab rodents $[12,13]$. Further analysis of the increasingly authenticated centenarian databases, e.g. the International Database on Longevity (IDL), shows that mortality plateaus are not defined until after age 110 in countries with the most rigorous data, when the annual probability of death reaches $>0.5$, 'consistent with a plateau around ages 110-114' [14]. However, in the recent analysis by Gavrilov and Gavrilova [15] of US Social Security data by cohort, mortality rates continued to increase up to the age of 106, following the Gompertz model, with no indications of a plateau; the mortality rate acceleration at ages $88-106$ was the same as calculated for 40-104. Ages after 110 are a difficult domain for demographic analysis because of health heterogeneity in the very few who reach $110,<1$ per million, most of whom are women.

Despite the exponential increase of centenarians over the last 50 years [16], Jeanne Calment's world record lifespan of 122.5 years in 1997 has not been surpassed. Using Gompertz parameters estimated from 630 birth cohorts born throughout the 19th and early 20th centuries and assuming the mortality conditions that characterize the 1920 cohort who would be now approaching 95, we cal-

Uneven Futures of Human Lifespans culated for a world population of 10 billion that the $\mathrm{L}_{\max }$ would be 120 years for women and 113 years for men [9]. These values closely match current records for each gender. The greater $\mathrm{L}_{\max }$ of women is a result of their lower mortality values $40-90$ and their slightly slower rates of mortality acceleration noted above. The unchallenged $\mathrm{L}_{\max }$ with faster mortality accelerations rising from lower background mortality also support the conclusions of Fries [17] and Olshansky et al. [18] that the current biological limits cannot be exceeded without major reduction of degenerative diseases and rates of aging.

Looking to the future, Christensen et al. [19] forecast survival probabilities of at least $50 \%$ from birth to age 100 in 21 st century birth cohorts for industrialized countries. This calculation assumes that mortality rates below age 50 are maintained at the 2006 year level, with a steady yearly increase of LE by 0.2 years. These LE forecasts are considerably longer than those computed for the US population [20]. Although the USA tends to have higher adult mortality rates than Europe, official Social Security projections of mortality decline estimate that less than $9 \%$ of the 2000 birth cohort will survive to age 100 .

As another approach to estimating recent cohort survival to later ages, we fitted a Gompertz mortality model for ages 40-90 in 8 European countries for cohorts born between 1800 and 1920 (fig. 1b, c). Assuming mortality rates at age 40 remain at the 2000 period level, we asked what Gompertz slope would be required for those born in 2000 to match the forecast of Christensen et al. [19] of an LE of 100. Figure 1c for 2000 shows that the Gompertz slopes required are $50 \%$ below those historically experienced. Such a large downshift of the Gompertz slope would require a fundamental slowing in the rate of aging. Another demographic model for an LE of 100 would be to delay the onset of the mortality acceleration curve, which is not evident in current trends.

Looking closer at these cohort data since 1900, we note a possible reversal or inflection of the Gompertz slope trend in 5 of 8 countries (fig. 1c) despite continued lowering of background mortality in these same cohorts (fig. 1b). This apparent deviation from long-term historical trends in the Strehler-Mildvan relationship will be discussed in a separate report.

Our reservations concerning the forecasted major increases for LE in the 21st century are shared by the recent analysis of Goldman et al. [21] that potential gains from a delayed aging scenario with reduced heart disease and cancer would only modestly increase LE at age 51 . If cancer and vascular conditions and the underlying aging processes become minimized by step-by-step engineering of neg- 
ligible senescence, as proposed by de Grey [22], then LE could be extended beyond its apparent $\mathrm{L}_{\max }$ [9]. Although we remain reserved about forecasts that centenarian lifespans would be achieved by $50 \%$ of births [19], animal models show these possibilities. In mouse mutants, the Gompertz mortality acceleration was slowed and its onset delayed by genetic manipulations of growth hormone [23] and mitochondrial catalase [24,25]. A human counterpart may be the lower incidence of cancer in Ecuadorian carriers of the Laron dwarf mutation, as in dwarf mice [26].

Another concern about forecasted major increases of LE is the emerging heterogeneity of survival at later ages, e.g. as described in the 2011 NAS report 'Explaining divergent levels of longevity in high-income countries' [27]. As one example of heterogeneity, US white females with $<12$ years of education have lost 5 years of LE from 1990 to 2008 [28]. The well-named 'obesity epidemic' continues to expand globally and is expected to offset some advances in medicine and technology. In addition to this well-recognized concern, we also believe the worsening climate will also have a negative impact.

Climate changes are upon us, with major implications for LE as well as health throughout life [3, 4]. The 2013 Federal Advisory Committee's Draft Climate Assessment Report [29] summarizes evidence that demonstrates a progressive increase of extreme weather events, including heat waves and heavy downpours, since 1960. Concurrent rises in sea levels increase brackish pools conducive for mosquitos and other insects, which probably increase insect-borne diseases $[3,4,30]$. Warming alone also increases ground-level ozone [3, 4], e.g. Southern California is expected to incur 6-30 more days per year of hazardous ozone by 2050 [31]. Besides the long-term trends for temperature, global air quality is worsening from increasing fossil fuel consumption. These and other factors threaten to diminish, or even reverse, the environmental and medical advances that enabled the increase in LE since 1800 .

One obvious concern to the elderly is heat waves, which are predicted to become increasingly frequent and intense $[3,4,32,33]$. The elderly are among the disadvantaged populations with particular vulnerability to the effects of climate change. In the killer summers of 1995 (USA) and 2003 (Europe) [32, 33], elderly men were particularly vulnerable. Elders with diabetes and congestive heart failure had an approximately threefold increase in mortality per $1{ }^{\circ} \mathrm{C}$ increase in summer temperature (Medicare data, 135 US cities) [34]. The majority of elderly reside in cities which are warmer by $1-4^{\circ} \mathrm{C}$ than the countryside ('urban heat islands') [4]. Many elderly cannot afford air conditioning, which is a major protective factor in heat vulnerability [35]. Although the threshold temperature for excess mortality differs between cities [34], there is consensus that increased mortality is highly likely because of the continuing increase in the number of days with extreme temperatures [4, 29]. Moreover, ozone and other air pollutants further increase mortality during heat waves [36].

Increasing fossil fuel consumption, besides contributing to global warming as a greenhouse gas, also produces airborne particulate material (PM). Particles with a diameter smaller than $2.5 \mu \mathrm{m}$ (PM2.5) from combustion engines are strongly associated with increased chronic diseases, including cancer and vascular disease. For example, in the Los Angeles basin, subclinical atherosclerosis (carotid intima media thickening) was increased by $5.9 \%$ per $10 \mu \mathrm{g} / \mathrm{m}^{3}$ PM2.5 (geocoded PM2.5 data) [37]. Moreover, transients in air pollution (1-7 days) were associated with increased myocardial infarctions by $2.5 \%$ per $100 \mu \mathrm{g} / \mathrm{m}^{3}$ PM2.5, and with smaller effects of $\mathrm{NOx}, \mathrm{SO}_{2}$, and ozone (meta-analysis of 34 studies) [38, 39]. An extreme example just reported from a regional analysis of China shows that household coal burning caused LE to decrease by 5.5 years, equivalent to loss of 2.5 billion life-years, alternatively calculated in terms of a 3-year loss of LE at birth per $100 \mu \mathrm{g} / \mathrm{m}^{3}$ total PM [40]. These findings are based on the epidemiology of cardiorespiratory mortality in North versus South China, geographically defined by the EastWest course of the Huai River. Households in North China have been given free coal since 1950 by the central government, with unintended dire consequences.

Globally, fossil fuel consumption is anticipated to increase by $50 \%$ up through 2040, approximately $2-3 \% /$ year [41]. Thus, the recent improvements of LE in developing countries may be eroded in conjunction with further economic growth. Besides demands for vehicular transportation and manufacturing, increased air conditioning also contributes to increased power needs. As a result, it will be very hard to diminish airborne PM in the developing world. Nonetheless, many countries, including China, have recognized the health burden of fossil fuels and are developing alternate energy sources. The next several decades may realize reduced global air pollution, with benefits to public health, as well as greenhouse gas emissions; however, we do not expect a quick fix. For example, China recently announced a policy to replace coal-powered electrical generation with natural gas in select zones [42]. Despite diminished airborne particulates, natural gas combustion still produces appreciable $\mathrm{CO}_{2}$ without additional scrubbing. 
The effects of air pollution also extend to the brain across the lifespan. Across the USA, $10 \mathrm{ppb}$ higher average ozone was associated with cognitive deficits during middle-age, equivalent to accelerating 'normative cognitive aging' by 4 years [43]. These trends are likely to increase because of warming-related atmospheric ozone, as noted above. The Finch lab is studying interactions of urban nano-sized PM $<0.25 \mu \mathrm{m}(\mathrm{nPM})$ in rodent models. Exposure to $150 \mathrm{~h}$ of nPM inhalation over 10 weeks induced brain glial inflammatory reactions and selective effects on glutamate receptor function [44]. In vitro, nPM rapidly induced the free radical NO with ensuing nitrosylation of glutamate receptors [45]. Moreover, gestational exposure of rats to nPM impaired postnatal neuronal differentiation and increased adult depressive behaviors [46]. Although our exposure model did not alter rodent birth weight, the International Collaboration of Air Pollution and Pregnancy Outcomes (ICAPPO) observed associations of PM10 with lower birth weight (-8.9 g per $10 \mu \mathrm{g} / \mathrm{m}^{3}$ of PM10) [47]. These early indications for a gestational impact of air pollution warrant further study for synergies with the many recognized developmental life influences on adult health and aging.

Increased infections are another concern of global climate change because warming alone enhances the growth of insect populations $[2-4,30,48-50]$. An example explored with detailed modeling is the tenfold increase of dengue fever, a mosquito-borne infection, in Singapore coinciding with a progressive increase in temperature over 15 years, i.e. 1989-2005 [48]. Extreme weather events with flooding and enlarged coastal brackish pools from rising sea levels are favorable breeding grounds for salinity-tolerant mosquitos and other insect vectors [30, 50]. Emerging shortages of water in many regions also chal- lenge hygiene and public health, with consequences for the very young as well as elderly. Thus, greater exposure to pathogens coupled with the adaptive immune responses of most elderly could increase their burden of infections. The very young are also at risk for mortality from rising levels of infections. These and other aspects of climate change warrant detailed study of their impact on the globally expanding elderly populations.

The socioeconomic polarization of LE [27] seems likely to persist globally despite remarkable recent gains in many developing countries [51]. A privileged few could experience minimal challenges from climate and environmental deterioration. The top socioeconomic strata already live in protected environments at work and home. The emerging marvels of regenerative medicine for organ replacement will likely be extremely expensive. We anticipate new drugs and other treatments to slow or even prevent atherosclerosis, Alzheimer's disease, and cancer, which might extend LE and current $\mathrm{L}_{\max }[9,12]$. However, such rejuvenating marvels may only be available to 'health elites' who can afford both protected environments and state-of-the-art medicine. Thus, we expect continuing socioeconomic disparities in adult health and longevity.

While this report was under review, Carnes et al. [52] published their perspective on climate change and elder health, reaching similar conclusions on several issues addressed herein.

\section{Acknowledgements}

The authors appreciate grant support from the NIH: CEF, R21 AG-040753 and P01 AG-040753 (RD Brinton, PI; CEF, Project 4); EMC, P30AG017265.

\section{References}

1 Oeppen J, Vaupel JW: Demography. Broken limits to life expectancy. Science 2002;296: 1029-1031.

-2 Finch CE, Crimmins EM: Response to comment on 'Inflammmatory exposure and historical changes in human life-spans'. Science 2005;308:1743, author reply 1743 .

3 Advancing the Science of Climate Change. Washington, National Academies Press, 2010.

4 Adapting to the Impacts of Climate Change. Washington, National Academies Press, 2010.

5 Finch CE, Crimmins EM: Inflammatory exposure and historical changes in human lifespans. Science 2004;305:1736-1739.
6 Crimmins EM, Finch CE: Infection, inflammation, height, and longevity. Proc Natl Acad Sci USA 2006; 103:498-503.

7 Fogel RW: The Escape from Hunger and Premature Death, 1700-2100: Europe, America, and the Third World. New York, Cambridge University Press, 2004.

8 Crimmins EM, Drevenstedt G, Finch CE: Evolution of the human mortality curve: changes in the age of minimum mortality (abstract). Popul Assoc Am 2007. http://paa2007. princeton.edu.

9 Beltrán-Sánchez H, Crimmins EM, Finch CE: Early cohort mortality predicts the cohort rate of aging: an historical analysis. J Dev Orig Adult Health Dis 2012;3:380-386.
10 Strehler BL, Mildvan AS: General theory of mortality and aging. Science 1960;132:1421.

11 Vaupel JW, Carey JR, Christensen K, Johnson TE, Yashin AI, Holm NV, Iachine IA, Kannisto V, Khazaeli AA, Liedo P, Longo VD, Zeng Y, Manton KG, Curtsinger JW: Biodemographic trajectories of longevity. Science 1998;280:855-860.

12 Finch CE, Pike MC: Maximum lifespan predictions from the Gompertz mortality model. J Gerontol 1996;51:B183-B194.

13 Austad SN: Concepts and theories of aging; in Masoro EJ, Austad SN (eds): Handbook of the Biology of Aging. San Diego, Academic Press, 2001, pp 3-22. 
14 Gampe J: Human mortality beyond age 110; in Maier H, Gampe J, Jeune B, Robine J-M, Vaupel JW (eds): Supercentenarians. Berlin, Springer 2010, pp 219-230.

15 Gavrilov LA, Gavrilova NS: Mortality measurement at advanced ages: a study of the social security administration death master file. N Am Actuar J 2011;15:432-447.

16 Robine J-M, Vaupel JW: Emergence of supercentenarians in low-mortality countries. $\mathrm{N}$ Am Actuar J 2002;6:54-63.

17 Fries JF: Aging, natural death, and the compression of morbidity. N Engl J Med 1980; 303:130-135.

18 Olshansky SJ, Carnes BA, Cassel C: In search of Methuselah: estimating the upper limits to human longevity. Science 1990;250:634-640.

19 Christensen K, Doblhammer G, Rau R, Vaupel JW: Ageing populations: the challenges ahead. Lancet 2009;374:1196-1208.

20 Bell FC, Miller ML: Life Tables for the United States Social Security Area 1900-2100. Actuarial Study No. 120. Washington, Social Security Administration, Office of the Chief Actuary, 2005.

-21 Goldman DP, Cutler D, Rowe JW, Michaud PC, Sullivan J, Peneva D, Olshansky SJ: Substantial health and economic returns from delayed aging may warrant a new focus for medical research. Health Aff (Millwood) 2013;32: 1698-1705.

22 de Grey AD: A divide-and-conquer assault on aging: mainstream at last. Rejuvenation Res 2013;16:257-258.

-23 Flurkey K, Papaconstantinou J, Miller RA, Harrison DE: Lifespan extension and delayed immune and collagen aging in mutant mice with defects in growth hormone production. Proc Natl Acad Sci USA 2001;98: 6736-6741.

-24 Schriner SE, Linford NJ, Martin GM, Treuting P, Ogburn CE, Emond M, Coskun PE, Ladiges W, Wolf N, Van Remmen H, Wallace DC, Rabinovitch PS: Extension of murine life span by overexpression of catalase targeted to mitochondria. Science 2005;308:1909-1911.

25 Mao P, Manczak M, Calkins MJ, Truong Q, Reddy TP, Reddy AP, Shirendeb U, Lo HH, Rabinovitch PS, Reddy PH: Mitochondriatargeted catalase reduces abnormal APP processing, amyloid $\beta$ production and BACE1 in a mouse model of Alzheimer's disease: implications for neuroprotection and lifespan extension. Hum Mol Genet 2012;21:29732990.

26 Guevara-Aguirre J, Balasubramanian P, Guevara-Aguirre M, Wei M, Madia F, Cheng CW, Hwang D, Martin-Montalvo A, Saavedra J, Ingles S, de Cabo R, Cohen P, Longo VD: Growth hormone receptor deficiency is associated with a major reduction in pro-aging signaling, cancer, and diabetes in humans. Sci Transl Med 2011;3:70ra13.

27 Crimmins EM, Preston SH, Cohen B (eds): Explaining Divergent Levels of Longevity in High-Income Countries. Washington, $\mathrm{Na}$ tional Academies Press, 2011.
Olshansky SJ, Antonucci T, Berkman L, Binstock RH, Boersch-Supan A, Cacioppo JT, Carnes BA, Carstensen LL, Fried LP, Goldman DP, Jackson J, Kohli M, Rother J, Zheng Y, Rowe J: Differences in life expectancy due to race and educational differences are widening, and many may not catch up. Health Aff (Millwood) 2012;31:1803-1813.

29 National Climate Assessment Draft 2013. Washington, National Academies Press, 2013. http://www.nap.edu/catalog.php?record_id= 18322.

30 Ramasamy R, Surendran SN: Global climate change and its potential impact on disease transmission by salinity-tolerant mosquito vectors in coastal zones. Front Physiol 2012;3: 198.

31 Kleeman MJ, Chen S-H, Harley R: Climate change impact on air quality in California. Report to the California Air Resources Board 2010. www.arb.ca.gov/research/apr/past/04349.pdf2.

32 Robine JM, Michel JP, Herrmann FR: Excess male mortality and age-specific mortality trajectories under different mortality conditions: a lesson from the heat wave summer 2003. Mech Aging Devel 2012;133:378-396.

33 Reid CE, O'Neill MS, Gronlund CJ, Brines SJ, Brown DG, Diez-Roux AV, Schwartz J: Mapping community determinants of heat vulnerability. Environ Health Perspect 2009;117: $1730-1736$

34 Zanobetti A, O’Neill MS, Gronlund CJ, Schwartz JD: Summer temperature variability and long-term survival among elderly people with chronic disease. Proc Natl Acad Sci USA 2012;109:6608-6613.

35 Theocharis G, Tansarli GS, Mavros MN, Spiropoulos T, Barbas SG, Falagas ME: Association between use of air-conditioning or fan and survival of elderly febrile patients: a prospective study. Eur J Clin Microbiol Infect Dis 2013;32:1143-1147.

36 Analitis A, Michelozzi P, D’Ippoliti D, de'Donato F, Menne B, Matthies F, Atkinson RW, Iñiguez C, Basagaña X, Schneider A, Lefranc A, Paldy A, Bisanti L, Katsouyanni K: Effects of heat waves on mortality: effect modification and confounding by air pollutants. Epidemiol 2013, in press.

-37 Künzli N, Jerrett M, Mack WJ, Beckerman B, LaBree L, Gilliland F, Thomas D, Peters J, Hodis $\mathrm{HN}$ : Ambient air pollution and atherosclerosis in Los Angeles. Environ Health Perspect 2005;113:201-206.

38 Mustafic H, Jabre P, Caussin C, Murad MH, Escolano S, Tafflet M, Périer MC, Marijon E, Vernerey D, Empana JP, Jouven X: Main air pollutants and myocardial infarction: a systematic review and meta-analysis. J Am Med Assoc 2012;307:713-721.

-39 Shah AS, Langrish JP, Nair H, McAllister DA, Hunter AL, Donaldson K, Newby DE, Mills NL: Global association of air pollution and heart failure: a systematic review and metaanalysis. Lancet 2013;382:1039-1048.
40 Chen Y, Ebenstein A, Greenstone M, Li H: Evidence on the impact of sustained exposure to air pollution on life expectancy from China's Huai River policy. Proc Natl Acad Sci USA 2013;110:12936-12941.

41 www.epa.gov/cleanenergy/energy-and-you/ affect/air-emissions.htm.

42 www.chinafaqs.org/blog-posts/can-china'saction-plan-combat-air-pollution-slowdown-new-coal-power-development\#fn1.

43 Chen JC, Schwartz J: Neurobehavioral effects of ambient air pollution on cognitive performance in US adults. Neurotoxicology 2009; 30:231-239.

44 Morgan TE, Davis DD, Iwata N, Tanner JM, Snyder D, Ning Z, Kam W, Hsu YT, Winkler JW, Chen JC, Petasis NA, Baudry M, Sioutas C, Finch CE: Glutamatergic neurons in rodent models respond to nanoscale particulate urban air pollutants in vivo and in vitro. Environ Health Perspect 2011;119:1003-1009.

- 45 Davis DA, Akopian G, Walsh JP, Sioutas C, Morgan TE, Finch CE: Urban air pollutants reduce synaptic function of CA1 neurons via an NMDA/NO pathway in vitro. J Neurochem 2013;127:509-519.

-46 Davis DD, Bortolato M, Godar SC, Sander TK, Iwata N, Pakbin P, Shih JC, Berhane K, McConnell R, Sioutas C, Finch CE, Morgan TE: Prenatal exposure to urban air nanoparticles in mice causes altered neuronal differentiation and depression-like responses. PLoS One 2013;8:e64128.

47 Dadvand P, Parker J, Bell ML, Bonzini M, Brauer M, Darrow LA, Gehring U, Glinianaia SV, Gouveia N, Ha EH, Leem JH, van den Hooven EH, Jalaludin B, Jesdale BM, Lepeule J, Morello-Frosch R, Morgan GG, Pesatori AC, Pierik FH, Pless-Mulloli T, Rich DQ, Sathyanarayana S, Seo J, Slama R, Strickland $M$, Tamburic L, Wartenberg D, Nieuwenhuijsen MJ, Woodruff TJ: Maternal exposure to particulate air pollution and term birth weight: a multi-country evaluation of effect and heterogeneity. Environ Health Perspect 2013;121:267-373.

48 Massad E, Coutinho FA, Lopez LF, da Silva DR: Modeling the impact of global warming on vector-borne infections. Phys Life Rev 2011;8:169-199.

49 Bezirtzoglou C, Dekas K, Charvalos E: Climate changes, environment, infection: facts, scenarios and growing awareness from the public health community within Europe. Anaerobe 2011;17:337-340.

50 Southerst RW: Global change and human vulnerability to vector-borne diseases. Clin Microbiol Rev 2005;36:689-696.

51 Salomon JA, Wang H, Freeman MK, Vos T, Flaxman AD, Lopez AD, Murray CJ: Healthy life expectancy for 187 countries, 1990-2010: a systematic analysis for the Global Burden Disease Study 2010. Lancet 2012;380:21442162.

52 Carnes BA, Staats D, Willcox BJ: Impact of climate change on elder health. J Gerontol A Biol Sci Med Sci 2013. E-pub ahead of print. 